\title{
Topiramate in the prevention and treatment of migraine: efficacy, safety and patient preference
}

This article was published in the following Dove Press journal:

Neuropsychiatric Disease and Treatment

22 December 2009

Number of times this article has been viewed

\section{Steffen Naegel \\ Mark Obermann \\ Department of Neurology, University of Duisburg-Essen, Hufelandstr. 55, \\ 45 I 22 Essen, Germany}

Correspondence: Mark Obermann Department of Neurology, University of Duisburg-Essen

Hufelandstr. 55, 45I 22 Essen, Germany

$\mathrm{Tel}+49-20 \mathrm{l}-723-84385$

Fax +49-20I-723-5542

Email mark.obermann@uni-due.de

\begin{abstract}
Migraine is a very common disorder characterized by the combination of typical headache with associated autonomic symptoms and/or the presence of aura. Considerable advances have been made in recent years to understand the pathophysiology of migraine, which has led to improved treatment options for the acute migraine attack as well as migraine prophylaxis. Unfortunately, preventive treatment is often insufficient to decrease migraine frequency substantially or is not well tolerated. Topiramate is an antipileptic drug with a complex mode of action which has proven its efficacy and safety in the prophylactic treatment of episodic migraine in a number of randomized controlled clinical trials. Topiramate is also effective in treating patients with chronic migraine. It has little pharmacological interaction with other drugs and is generally well tolerated by patients.
\end{abstract}

Keywords: migraine, antiepileptic drugs, topiramate

\section{Introduction}

Migraine is the second most common form of headache after episodic tension-type headache. Epidemiological studies have documented its high prevalence and high socioeconomic impacts. It is ranked by the World Health Organization as number 19 among all diseases worldwide causing disability. ${ }^{1,2}$ Migraine is characterized by unilateral location, but may also be bilateral, pulsating, of moderate to severe intensity, aggravated by routine physical activity and associated with nausea and/or photophobia and phonophobia. Attacks usually last between 4 and 72 hours. $^{3}$ A typical feature of migraine is that headache may change sides from attack to attack in contrast to trigeminal autonomic cephalalgias in which the headache in general is side-locked.

Lifetime prevalence is as high as $14 \%$, with a male to female ratio that varies for adults from 1:2 to $1: 3 .{ }^{1}$ Current prevalence of migraine was estimated at $10 \%{ }^{2}$ Women have more migraine without aura than migraine with aura. The most common age of onset of migraine is in the second and third decades of life. The prevalence of migraine increases with age until a peak is reached during the fourth decade after which the prevalence declines, with a more pronounced decline in women than in men. ${ }^{1}$ Migraine prevalence varies with age. Two different studies investigated the prevalence of migraine before the age of 20 and beyond the age 65 years. A Brazilian study found a 1 -year migraine prevalence of $10.6 \%$ with a male to female ratio of $5.1 \%$ to $14.1 \%$ in patients older than 65 years. ${ }^{4}$ The youth part of the Head-HUNT study found a 1 -year overall prevalence of $7.1 \%$ among investigated subjects between the ages of 12 and 19 years. ${ }^{5}$ 
In a population-based study $27 \%{ }^{6}$ and $45.8 \%$ of migraine patients in a tertiary referral center ${ }^{7}$ have strictly unilateral headache with unilateral autonomic features (UAs) such as ipsilateral conjunctival injection, ipsilateral tearing, ipsilateral nasal congestion or rhinorrhea, ipsilateral eyelid edema, ipsilateral miosis or ptosis, and ipsilateral forehead or facial sweating. A recent population-based study demonstrated of these migraine patients $43.4 \%$ reported to have only 1 UA during the migraine attack regularly, ${ }^{6} 34.3 \%$ reported to have $2,15.4 \%$ had $3,4.9 \%$ had 4 , and $2.1 \%$ reported to have 5 UAs during their migraine attack. Migraine patients with UAs experienced their head pain strictly more often unilateral (38.5\%) than non-UA patients $(20.1 \%)$. These patients with UAs also experienced a greater increase in pain intensity during a migraine attack than non-UA migraine patients (mean visual analog scale: 7.4 vs 5.2), but no reasonable pattern was observed in the correlation of the number of UAs to pain intensity in this respect. ${ }^{6}$

Nearly $30 \%$ to $40 \%$ of migraine patients experience transient focal neurological symptoms before headaches occur; ${ }^{8-11}$ this so-called aura is visual in most cases, but other sensory and motor symptoms may occur. ${ }^{12}$ Aura slowly develops over several minutes and usually lasts approximately 15 to 60 minutes. Many migraine patients describe a premonitory phase, which may begin up to 2 days before the headache itself. Symptoms of this premonitory phase are unspecific. Hyper- or hypoactivity, dizziness, neck stiffness, craving for food, yawning, or even sensitivity for light and sound were described. ${ }^{13}$

Major goals in migraine therapy are lifting the burden, and improving the quality of life by reducing migraine frequency, severity, duration and disability during and between attacks thus enabling patients a normal function in everyday life routines. Even though migraine therapy and migraine acceptance has come a long way over the past decade, it still remains a frequently undertreated condition. ${ }^{14,15}$ The treatment of migraine consists of three major steps: 1) elimination of environmental and psychosocial factors that may worsen or contribute to the development of headache, 2) adequate and sufficient acute therapy, and 3) prophylactic treatment, which should be considered and recommended to patients with high attack frequency, severe attack intensity or very disabling aura phenomena. Table 1 gives an overview of drugs commonly used in migraine therapy and prophylaxis, as well as their side effects and contraindications.

In general, a timely start of preventive treatment has to be considered in patients suffering from migraine with high impact on daily activities and overall functioning. Many different substances were tested in regard to their prophylactic effects on migraine. Some proved efficient in multicenter, randomized, controlled clinical trials and thus were recommended by current European and US treatment guidelines for the standardized, evidence based treatment of migraine. ${ }^{16,17}$ One of the latest drugs with proven efficacy in migraine prophylaxis is topiramate. Three large, controlled, clinical trials have been conducted over recent years. Topiramate is a sulfamate-substituted monosaccharide, related to fructose. It is rapidly absorbed (peak plasma concentrations about 2 hours after intake) with a high bioavailability ( $81 \%$ to $95 \%$ ). The major fraction of topiramate is eliminated primarily as unchanged drug. It shows linear steady-state pharmacokinetics, and its elimination half-life in monotherapy ranged from 19 to 25 hours in healthy volunteers after single-dose oral administration. ${ }^{18}$

Topiramate was initially approved in 1995 in the UK as adjunctive treatment of partial-onset seizures in adult epilepsy patients. ${ }^{19}$ Although the different mode of action have not yet been conclusively unraveled, there is evidence that the antiepileptic potential is not based on its specific impact on a singule channel or a particular channel subtype, but on several different mechanisms of action. Topiramate blocks voltage-dependent sodium and calcium channels. ${ }^{20,21}$ It also inhibits the excitatory glutamate pathway while enhancing the inhibitory effect of GABA..$^{22,23}$ Moreover, it inhibits carbonic anhydrase activity. ${ }^{24}$ The relevant mechanism of action responsible for efficient migraine prophylaxis remains to be determined.

This review will summarize current knowledge about the treatment of migraine with topiramate. A MEDLINE search (October 20th, 2009) for articles containing "topiramate" and "migraine" was performed and returned 321 articles, of which 103 were marked as review articles. The focus will be directed on recent randomized, controlled, clinical trials on the efficacy and safety of topiramate in prophylactic treatment of migraine in general and treatment of chronic migraine in particular.

\section{Prophylactic treatment of episodic migraine with topiramate}

Most migraine patients are treated or treat themselves with acute attack/rescue medication. Prophylactic migraine treatment is much more uncommon. Even though as early as 1966 the prophylactic effect of the unselective beta-blocker propranolol was first described in migraine ${ }^{25,26}$ long before a commonly accepted definition of migraine was released by the International Headache Society in $1988 .{ }^{27}$ Several international guidelines have been published on treatment 
Table I Substances used for migraine treatment recommended by EFNS Guideline on the treatment of migraine ${ }^{16}$

\begin{tabular}{|c|c|c|c|c|}
\hline LR & Substance & Dose (if not given in $\mathbf{m g}$ ) & Side effects & Contraindications \\
\hline \multicolumn{5}{|c|}{ Acute migraine treatment } \\
\hline A & ASA & 1000 (oral) 1000 (iv) & $\begin{array}{l}\text { gastrointestinal side effects, } \\
\text { abdominal pain, clotting } \\
\text { abnormality, risk of bleeding }\end{array}$ & $\begin{array}{l}\text { gastric ulcer, bleeding diathesis, } \\
\text { pregnancy (months 7-9) }\end{array}$ \\
\hline A & Ibuprofen & $200-800$ & side effects as for ASA, edema & $\begin{array}{l}\text { like ASA (less bleeding tendency), } \\
\text { renal failure, pulmonary embolism }\end{array}$ \\
\hline A & Naproxen & $500-1000$ & like ibuprofen & like ibuprofen \\
\hline A & $\begin{array}{l}\text { Acetaminophen/ } \\
\text { paracetamol }\end{array}$ & I000 (oral or suppository) & liver damage & liver and kidney failure \\
\hline A & Diclofenac & $50-100$ & like ibuprofen & like ibuprofen \\
\hline A & $\begin{array}{l}\text { ASA plus paracetamol } \\
\text { plus caffeine }\end{array}$ & $\begin{array}{l}250 \text { (oral) } \\
200-250 \\
50\end{array}$ & see ASA and paracetamol & see ASA and paracetamol \\
\hline B & Metamizol & 1000 (oral) 1000 (iv) & $\begin{array}{l}\text { allergic reaction, changes in blood } \\
\text { count, risk of agranulocytosis in iv } \\
\text { use risk of hypotension }\end{array}$ & hematopoietic system disease \\
\hline B & Phenazon & 1000 (oral) & see paracetamol & unknown \\
\hline B & Tolfenamic acid & 200 (oral) & side effects as for ASA & unknown \\
\hline A & Sumatriptan & $\begin{array}{l}25,50,100 \text { (oral) } \\
25 \text { (suppository) } \\
10,20 \text { (nasal spray) } \\
6 \text { (subcutaneous) }\end{array}$ & $\begin{array}{l}\text { angina, nausea, distal paresthesia, } \\
\text { fatigue sensation of cold in } \\
\text { subcutaneous use - local skin } \\
\text { reaction at injection site }\end{array}$ & $\begin{array}{l}\text { arterial hypertension (untreated), } \\
\text { coronary heart disease, peripheral } \\
\text { artery occlusive disease, } \\
\text { cerebrovascular disease, multiple } \\
\text { vascular risk factors, Raynaud's } \\
\text { disease, pregnancy, lactation, age } \\
\text { under I8 (except sumatriptan } \\
\text { nasal spray), severe liver or kidney } \\
\text { failure, age above } 65 \text {, simultaneous } \\
\text { treatment with ergotamine, } \\
\text { within } 2 \text { weeks after break off from } \\
\text { treatment with a MAO inhibitor }\end{array}$ \\
\hline A & Zolmitriptan & $\begin{array}{l}2.5,5 \text { (oral) } \\
2.5,5 \text { (nasal spray) }\end{array}$ & see sumatriptan & see sumatriptan \\
\hline A & Naratriptan & 2.5 (oral) & $\begin{array}{l}\text { see sumatriptan (probably milder/ } \\
\text { fewer side effects) }\end{array}$ & see sumatriptan \\
\hline A & Rizatriptan & $\begin{array}{l}\text { I0 (oral) } \\
5 \mathrm{mg} \text { (when additionally } \\
\text { on propranolol) }\end{array}$ & see sumatriptan & see sumatriptan \\
\hline A & Almotriptan & I 2.5 (oral) & $\begin{array}{l}\text { see sumatriptan (probably milder/ } \\
\text { fewer side effects) }\end{array}$ & see sumatriptan \\
\hline A & Eletriptan & $\begin{array}{l}20,40 \text { (oral) } \\
80 \text { allowed if } 40 \text { not effective }\end{array}$ & see sumatriptan & see sumatriptan \\
\hline A & Frovatriptan & 2.5 (oral) & $\begin{array}{l}\text { see sumatriptan (probably milder/ } \\
\text { fewer side effects) }\end{array}$ & see sumatriptan \\
\hline \multicolumn{5}{|c|}{ Prophylactic migraine treatment } \\
\hline A & Propranolol & 50-200 & $\begin{array}{l}\text { oft: fatigue, arterial hypotension } \\
\text { occ.: sleep disturbances, dizziness } \\
\text { s: hypoglycemia, bronchospasm, } \\
\text { bradycardia, gastrointestinal side } \\
\text { effects, impotence }\end{array}$ & $\begin{array}{l}\text { a:AV block, bradycardia, asthma anc } \\
\text { sick sinus syndrome } \\
\text { r: diabetes mellitus, depression, } \\
\text { diabetes mellitus, orthostatic } \\
\text { disregulation }\end{array}$ \\
\hline
\end{tabular}


Table I (Continued)

\begin{tabular}{|c|c|c|c|c|}
\hline LR & Substance & Dose (if not given in $\mathrm{mg}$ ) & Side effects & Contraindications \\
\hline$A$ & Flunarizine & $5-10$ & $\begin{array}{l}\text { oft: fatigue, weight gain } \\
\text { occ: gastrointestinal side effects, } \\
\text { depression } \\
\text { s: hyperkinesia, tremor, parkinsonism }\end{array}$ & $\begin{array}{l}\text { a: focal dystonia and depression, } \\
\text { pregnancy and lactation } \\
\text { r: familiar parkinsonism }\end{array}$ \\
\hline A & Valproic acid & $500-1800$ & $\begin{array}{l}\text { oft: fatigue dizziness, tremor } \\
\text { occ: exanthema, hair loss, weight gain } \\
\text { s: elevation of liver enzymes/ } \\
\text { disturbance in liver function }\end{array}$ & $\begin{array}{l}\text { a: liver failure, pregnancy, alcoholism, } \\
\text { polycystic ovaries }\end{array}$ \\
\hline A & Topiramate & $25-100$ & $\begin{array}{l}\text { oft: fatigue, cognitive disturbance, } \\
\text { weight loss, paresthesia } \\
\text { occ: change in taste, psychosis } \\
\text { s: glaucoma }\end{array}$ & $\begin{array}{l}\text { a: renal insufficiency, nephrolithiasis, } \\
\text { glaucoma }\end{array}$ \\
\hline B & Amitriptyline & $50-150$ & $\begin{array}{l}\text { oft: dry mouth, fatigue, dizziness, } \\
\text { sweating } \\
\text { occ: constipation, impotence, } \\
\text { incontinence, restlessness }\end{array}$ & $\begin{array}{l}\text { a: glaucoma, prostatic adenoma and } \\
\text { hyperplasia } \\
\text { r: heart insufficiency }\end{array}$ \\
\hline B & Venlafaxine & $2 \times 75-150$ & $\begin{array}{l}\text { oft: fatigue, loss of concentration } \\
\text { s: impotence, arterial hypertension }\end{array}$ & a: severe hypotension \\
\hline B & Naproxen & $2 \times 250-500$ & gastrointestinal side effects & $\begin{array}{l}\text { a: gastric ulcer, bleedings } \\
\text { r: asthma bronchiale }\end{array}$ \\
\hline B & Petasites & $2 \times 75$ & $\begin{array}{l}\text { occ: burping, gastrointestinal side } \\
\text { effects } \\
\text { s: liver disturbances }\end{array}$ & a: pregnancy and lactation \\
\hline B & Bisoprolol & $5-10$ & see metoprolol and propranolol & \\
\hline C & \multicolumn{4}{|c|}{$\begin{array}{l}\text { Gabapentin (1200-1600 mg), Magnesium ( } 24 \mathrm{mmol}) \text {, Tanacetum parthenium }(3 \times 6.25 \mathrm{mg}) \text {, Riboflavin }(400 \mathrm{mg}) \text {, Coenzyme Q } 10 \text { (300 mg), } \\
\text { Candesartan (16 mg), Lisinopril ( } 20 \mathrm{mg}) \text {, Methysergide (4-12 mg) }\end{array}$} \\
\hline
\end{tabular}

Notes: Evidence class A indicates the presence of multiple randomized controlled clinical trial; evidence class B indicates one randomized trial exists or multiple uncontrolled trials were performed; evidence class $C$ refers to common expert opinion or single case reports.

Abbreviations: ASA, acetylsalicylic acid; AV, atrioventricular; oft, often; occ, occasionally; s, seldom; a, absolute; r, relative; LR, level of recommendation; MOA, monoamine oxidase inhibitor.

indications, choice of drugs, and treatment options and goals. Although these guidelines are to some extent diverse, there is consensus that the indication for the start of prophylactic treatment should be well discussed with the patient and patient preference should be considered. The most important points in the decision on whether prophylactic therapy is required are frequency and severity of migraine and its impact on quality of life. Possible problems with acute medication should be considered (eg, overuse, adverse events, contraindications, absence of efficacy) as well as possible side effects and efficacy of prophylactic treatment. Important for the compliance of the patient to prophylactic therapy is the adjustment of patients' expectations to an adequate level, for example, complete freedom from headache is not a realistic goal. ${ }^{25}$ Appropriate goals of preventive therapy are: 1) reduced attack frequency, severity and duration; 2) improved response to acute attack treatment; 3 ) improved quality of life and reduced disability. In a recent study Lipton et al investigated the probable need for preventive therapy in the US. ${ }^{28}$ This was assessed following operational criteria defining reasonable starting points of preventive therapy. These criteria were developed by an expert panel to provide an objectively comparable benchmark. Authors found that $25.7 \%$ met criteria for "offer prevention" and in an additional $13.1 \%$ that prevention should be considered. Just $12.4 \%$ reported current use of daily preventive migraine medication. This indicates that preventive treatment still is severely underutilized. These figures are similar in France (6\%) and worse in Latin America (2\%). ${ }^{28-30}$

After some preliminary analyses, and open-label and small controlled studies ${ }^{31-34}$ reported topiramate to be effective in preventive migraine therapy, three large placebocontrolled trails (two North American and one European) were published in 2004, which investigated the efficacy and safety of preventive migraine treatment with topiramate. ${ }^{19,35,36}$ All three studies used a similar study design. After 14 days washout and a 28-day prospective baseline period, different topiramate doses were tested in a $26(8+18)$-week doubleblind (DB) phase against placebo. In the two northern American trials (MIGR-001 and MIGR-002, with 49 and 
52 participating centers) topiramate target doses of 50, 100 and $200 \mathrm{mg}$ /day were tested against placebo, and in the European trial (MIGR-003 with 61 participating centers) only two different daily doses of topiramate (100 and $200 \mathrm{mg}$ /day) were tested. In addition to the placebo group a blinded active control group receiving propranolol for preventive treatment was carried out in the European trial only. Inclusion criteria in all three trials were: i) patients aged 12 to 65 years with an established history of migraine with or without aura (assessed using ICHD-I criteria ${ }^{27}$ ) and ii) 3 to 12 migraine headache days and iii) not more than 15 headache days (migraine or nonmigraine) during the baseline phase. A headache day was defined as a calendar day during which a patient experienced headache for at least 30 minutes. The 26 -week double-blind phase started with an 8-week titration period $(25 \mathrm{mg} /$ day starting dose and weekly increase of $25 \mathrm{mg}$ ). In each trial this increase was performed up to the previously assigned dose or maximal tolerated dose. After titration, the double blind period was completed after an 18-week maintenance phase. The study drugs were administered in two equally divided daily doses. In all three trials patients were permitted to take acute/rescue medications. Exclusion criteria were largely similar in all trials, including overuse of acute migraine therapies, medications potentially interfering with study outcome and headaches other than migraine.

The primary efficacy measure in all trials was the change of mean monthly (28 days) migraine frequency from baseline through the entire DB period. Significance was tested between the treatment groups and placebo. Frequency was measured with headache diaries using the concept of migraine period, defined as any occurrence of migraine headache that started, ended or recurred within 24 hours. Pain lasting longer than 24 hours after its initial onset constituted a new, distinct migraine period. The secondary outcome variables were largely similar in all studies as well including time of topiramate action onset, proportion of subjects responding to treatment (defined as at least 50\% monthly migraine frequency reduction), mean change in monthly migraine days as well as change in number of days per month requiring rescue medication compared to baseline. Some trials also reported the change in duration and severity of migraine attacks. Due to the similarity in study design and chosen endpoints, a pooled analysis with all patients from the three trials randomized to topiramate $100 \mathrm{mg} /$ day was performed by Bussone et al in 2005. ${ }^{37}$

Pooling all controlled trials, more than 1500 patients were randomized and included in the intent to treat (ITT) cohorts. From these, 663 withdrew from trials due to adverse events, lack of efficacy, own choice or lost to follow up (220, 228, 215 , respectively) (see Table 2 for details on withdrawal rates). Although adverse events had been the most common reason for withdrawal in all topiramate groups, patients randomized to placebo most often withdrew because of lack of efficacy. In all three studies baseline clinical and demographic characteristics were well balanced between groups. The results of the different trials are similar. All trials showed that prophylactic treatment with topiramate reduced migraine frequency considering the mean change in monthly migraine periods compared to baseline with the $100 \mathrm{mg} /$ day dose. While the North American trials showed a reduction in mean monthly migraine frequency for the 200-mg/day group, the European trial failed to do so. The authors suggested that this was due to the high rate of withdrawal in this treatment group (79 of 144 patients randomized; 63 due to adverse events [AE]). A daily dose of $50 \mathrm{mg}$ showed a reduction in mean monthly migraine frequency which was not significant compared to placebo. In all trials $100 \mathrm{mg}$ /day topiramate showed a significant onset of action within the first month. Propranolol, used only in the European trial, also showed efficacy within the first month of treatment. Interestingly, in all groups treated with topiramate $(50,100$ or $200 \mathrm{mg})$ responder rate was higher compared to placebo regardless of whether it

Table 2 Topiramate common interactions

\begin{tabular}{ll}
\hline Interacting drug & Form of interaction \\
\hline Phenytoin & $\begin{array}{l}\text { Decrease of plasma concentration of topiramate } \\
\text { Increase plasma level of phenytoin }\end{array}$ \\
Carbamazepine & $\begin{array}{l}\text { Decrease of plasma concentration of topiramate } \\
\text { Digoxin }\end{array}$ \\
Estrogens & $\begin{array}{l}\text { single shot of topiramate [found in a single trial]) } \\
\text { Decrease in effectiveness of oral contraception } \\
\text { (seen in 200 mg, } 400 \text { mg and } 800 \text { mg daily doses } \\
\text { of topiramate) }\end{array}$ \\
Hydrochlorothiazide & $\begin{array}{l}\text { Increase of topiramate plasma levels; higher } \\
\text { decrease in plasma potassium levels as usual }\end{array}$ \\
Lithium & $\begin{array}{l}\text { Change of lithium plasma concentration } \\
\text { Reduction of topiramate oral plasma clearance; } \\
\text { Metformin }\end{array}$ \\
increase of metformin plasma level \\
Pioglitazone
\end{tabular}


significantly reduced mean migraine frequency. In contrast, the reduction in mean rescue medication days was significant only in groups in which the primary efficacy measure was also significant (MIGR-001: topiramate 100: -1.9 days, topiramate 200: -2.1 days; MIGR-002: topiramate 100: -2.1 days, topiramate 200-2.2 days; MIGR-003: topiramate 100-1.5 days, propranolol: -1.6 days; overall placebo -0.8 to -1.0 days). In MIGR-002 change in average duration for $200 \mathrm{mg} /$ day and change in pain severity for $100 \mathrm{mg}$ /day was significant.

Some additional information was derived from the pooled analysis due to the 3 -fold increase in patient numbers. The change in monthly migraine frequency was reassessed, including number of migraine periods, number of migraine attacks, and number of migraine days. All three variables showed significant reduction compared to placebo. The high number of analyzed patients allowed a gender-specific analysis, which showed that the therapeutic effect was independent of gender. The monthly migraine duration was significantly changed from baseline by $-46.5 \%$ compared to $-20 \%$ in placebo group $(P<0.05)$. In summary, there is sufficient scientific evidence showing topiramate is effective in reducing migraine frequency at a dose of $100 \mathrm{mg} /$ day.

\section{Long-term prophylaxis with topiramate}

Some experts recommend a minimal duration of 6 to 12 months for preventive migraine therapy before a drug holiday should be considered. ${ }^{25}$ Most patients, however, will require a longer treatment period. Clinical trials that assessed the efficacy of migraine prevention over more than 1 year are scarce. ${ }^{38,39}$ To demonstrate that topiramate is effective and well tolerated when used for preventive migraine therapy up to 14 months, an 8-month open label extension (OLE) of the two large North American trials (MIGR-001 and MIGR-002) was performed. ${ }^{40}$ To enter this extension period, patients were required to have completed the DB phase or to have withdrawn after 4 weeks due to lack of efficacy. All eligible patients ( $\mathrm{n}=567,159$ received placebo, 408 on topiramate) were titrated to a clinical effective dose over a 7-week period. During the OLE phase further decrease in mean monthly migraine frequency was observed in subjects who received topiramate and in patients who were switched from the placebo group. But the slight additional improvement during these 8 months appeared not to be significant in the group with previous topiramate intake. Similar to the original trials the topiramate-associated reduction in mean migraine frequency assessed in the group that previously received placebo during the DB phase was observed after the first month of topiramate therapy. Furthermore, significant reductions observed in patients treated with 100 and $200 \mathrm{mg}$ /day topiramate a day were sustained over the 8 months OLE phase. The authors concluded that the clinical benefit appears to be sustained in patients treated with topiramate over 1 year and that there was no loss of efficacy over time, even when patients switched from a higher to a lower dose.

In 2007 a randomized, controlled clinical trial introduced a novel and very interesting study design. All patients were treated with topiramate in an open-label fashion for a period of 26 weeks, then randomized into topiramate and placebo groups. ${ }^{41}$ After a 4 - to 8 -week titration period (starting dose $25 \mathrm{mg}$ /day topiramate, increase $25 \mathrm{mg} /$ week weekly, target dose $100 \mathrm{mg}$ /day) 818 patients entered a 26-week open-label (OL) phase with further dose adjustments (range 50 to $200 \mathrm{mg}$ /day) and received a stable dose for the last 4 weeks within this 26-week period. 514 patients (of 559 patients that completed the OL phase) entered the following 26-week double-blind phase in which patients were randomly assigned to continue their dose $(n=255)$ or switched to placebo $(n=259)$. While in OL phase the most common reason for discontinuation was insufficient tolerability (21\%), in DB phase insufficient efficacy was the most common reason ( $7 \%$ in topiramate, $13 \%$ in placebo). During the OL phase the mean number of migraine days per 4 weeks decreased from OL baseline to the last 4 weeks (-3.09 migraine days; $P<0.0001)$. After the open label phase the number of migraine days (comparing the last 4 weeks of OL with the last 4 weeks of DB) increased in both groups as expected. The mean increase was greater in the placebo group (1.19 days, $P<0.0001)$ than in the topiramate group $(0.10, P=0.5756)$, but it did not return to baseline value $(P<0.0001)$. The differences between both groups were statistically significant $(-1.09, P=0.0011)$. The change in number of migraine days showed a sharp increase within the first 4 weeks on placebo, while the topiramate group showed only a slight increase after entering the DB phase. The difference between treatment groups remained significant throughout the whole DB phase except between weeks 9 and 16. Duration of migraine headaches remained the same in both groups, while headache severity did not change in the topiramate group between OL and DB but slightly increased in the placebo group. Furthermore, patients in the placebo group had a greater increase in days on acute medication from OL than those in the topiramate group (mean difference -0.95 days, $P=0.0007$ ). To assess health-related quality of life three questionnaires were used in this trial. The six-item headache impact test $\left(\right.$ HIT-6) ${ }^{42}$ showed no significant difference, but differences 
between topiramate and placebo groups were observed in the Migraine Disability Assessment (MIDAS) questionnaire. ${ }^{43}$ The MIDAS increased from start to end of the DB phase by 6 points in the placebo group while the topiramate group remained unchanged. The short form 12 general health questionnaire (SF-12) $)^{44}$ also showed a benefit in physical component score for topiramate. Moreover, patients who received topiramate were more satisfied with the efficacy of therapy than those receiving placebo, whereas tolerability was similar in both treatment groups. The authors concluded that patients who discontinued therapy/received placebo had an increase in number of migraine days and a lower quality of life than patients still receiving topiramate. An interesting finding is that patients may also have a persistent benefit from topiramate even when discontinued, because the number of migraine days in most patients did not increase to pretreatment values.

\section{Treatment of chronic migraine with topiramate}

Headache is a very dynamic disease. The transition from episodic to chronic migraine is not uncommon. Approximately $3 \%$ to $4 \% \%^{2,28,45,46}$ of the general population suffer from chronic daily headache that was defined by Silberstein et al as headache lasting at least 4 hour per day with over 15 headache days per month. ${ }^{47}$ Chronic migraine (CM), chronic tension type headache (CTTH) and medication overuse headache $(\mathrm{MOH})$ are the most common forms of chronic daily headache. ${ }^{45}$ The most important risk factors for the development of $\mathrm{CM}$ are medication overuse and a high baseline attack frequency. ${ }^{48}$ The revised ICHD-2 defines CM as headaches occurring $\geq 15$ days per month, with at least 8 attacks fulfilling criteria for migraine without aura or responding to acute migraine medication (ie, triptans). ${ }^{49}$ Alternative definitions for $\mathrm{CM}$ are being discussed in the literature and final consensus has not yet been reached.

Topiramate has been reported to reduce migraine frequency in chronic migraine in some smaller clinical trials. ${ }^{50-52}$ A pooled analysis performed by Limmroth et al concluded that preventive treatment with topiramate in patients with episodic migraine may reduce the risk of developing chronic forms of headache. ${ }^{53}$ Two large, randomized, double-blind, placebocontrolled, parallel-group clinical trials were performed with topiramate in patients with CM. In general, these trials seem to be quite similar in design (CM with and without overuse, 16-week DB phase, $100 \mathrm{mg}$ topiramate target dose), but there are some key differences between these trials that must be considered when interpreting results. In the US trial with an intent-to-treat population of 306 patients total, the criteria for transformed migraine postulated by Silberstein and Lipton were used. ${ }^{54}$ No concomitant migraine preventive therapy was allowed and acute medication use was permitted on no more than 4 days a week. In contrast, the European trial ${ }^{55}$ used the unrevised criteria of ICHD-II, ${ }^{3}$ the intent to treat population was much smaller $(n=59)$, but the percentage of patients with an observed overuse during baseline was more than twice as high as in the US trial (78\% vs 37.6\%). The target dose in the European trial was also $100 \mathrm{mg} /$ day, but flexible dose titration was allowed from $50 \mathrm{mg}$ /day up to $200 \mathrm{mg}$ /day. Medication overuse was allowed without any restriction, as was the intake of concomitant different migraine preventive therapy, except other antiepileptic drugs. Inclusion criteria and allowed rescue medication also differed between trials. The primary outcome variable was also different: in the US trial change from baseline in mean monthly migraine/migrainous days over the entire DB phase was the main outcome measure, while in the European trial the change in mean monthly migraine days at the end of the DB phase was the main outcome variable. These differences have to be kept in mind when interpreting results. These studies are not completely comparable.

In the US trial a significant reduction in the mean monthly rate of migraine/migrainous days $(6.4 \pm 5.8)$, compared to placebo $(4.7 \pm 6.1 ; P=0.010)$ and a mean reduction from baseline of migraine days per month $(5.6 \pm 6.0)$ compared to placebo $(4.1 \pm 6.1 ; P=0.032)$ was found. In the European trial reduction in mean monthly migraine days $(-3.5 \pm 6.3)$ was found compared to placebo $(0.2 \pm 4.7 ; P=0.02)$. In this analysis patients with medication overuse reported mean monthly migraine days reduction by $3.5 \pm 7.1$ days, which was significant compared to placebo with an increase of $0.8 \pm$ 4.8 days $(P=0.03)$. Similar data on medication overuse were unavailable from the US trial, but a secondary analysis was performed and showed a trend towards significant group differences $(P=0.059) .{ }^{56}$ In the European trial the responder rate of at least $50 \%$ in reduction of migraine days was significant for topiramate ( $22 \%$ vs $0 \% P=0.012)$, but not in the US trial in which only the under $25 \%$ reduction in migraine/migrainous days responder rates showed significance. ${ }^{57}$ Patients' disability and quality of life evaluation results were different in both trials. While HIT-6 and Migraine Specific Questionnaire (MSQ) total scores did not show a significant change compared to placebo, the MIDAS score did in the European but not in the US trial. In contrast, in the US trial the role restrictive (RR) and emotional function (EF) domains of the MSQ showed significant differences in favor of topiramate. ${ }^{57}$ In the assessment of acute medication use, both trials were unable to show significant differences compared to placebo, but 
patients' treatment contentment was better in patients receiving topiramate than in those receiving placebo in both trials.

Topiramate $100 \mathrm{mg}$ /day seems to be effective in the treatment of chronic migraine. Lower dosage of $50 \mathrm{mg} /$ day may also be effectivel. ${ }^{51}$ General treatment effect appears to be independent from medication overuse, thus it may not be necessary to withdraw patients with $\mathrm{CM}$ from medication overuse prior to a treatment attempt with topiramate.

\section{Safety of topiramate treatment}

Topiramate is generally considered to be safe and well tolerated in migraine treatment. The most common $\mathrm{AE}$ in the currently published large, controlled clinical trials were paresthesia, fatigue, anorexia and nausea. It seemed that AE occurred more often in patients treated with topiramate $200 \mathrm{mg}$ (TPM 200) than in those treated with lower doses. This observation was very distinct in the European trial; here dropout rates due to AE were much higher in the TPM 200 group. No clinically important change in laboratory test results, vital signs or clinical examination was described in these trials. However, AE for cognitive symptoms (difficulty with memory, concentration/attention or speech problems) were seen in more than $10 \%$ of patients receiving topiramate, while only few patients receiving placebo were affected by such AE. This also seemed to be dose-dependent and more pronounced in the TPM 200 group. A pooled analysis including 758 patients (386 on $100 \mathrm{mg} /$ day topiramate, 372 on placebo) was performed. ${ }^{37}$ Paresthesia seems to be the most common AE with an incidence of $50.5 \%$, but like most other AE more than $90 \%$ of patients suffering from it described it to be mild to moderate. Treatment is usually not necessary as the numbness and tingling are self-limiting, but use of potassium supplements may provide relief. ${ }^{58}$ Fatigue, which was the second most common AE, was nearly as common in the placebo group as in the topiramate (TPM 15\%, placebo 11.8\%) group. Other common AE were anorexia (TPM 14.5\%, placebo $5.9 \%$ ), upper respiratory tract infection (TPM 14\%, placebo $12.6 \%$ ), nausea (TPM 13.2\%, placebo 8.9\%) and diarrhea (TPM 11.1\%, placebo 4.3\%). All other AE were reported in less than $10 \%$ of patients in the topiramate group, and included weight decrease, dizziness, taste perversion, hypoesthesia, insomnia, difficulty with memory, somnolence, language problems, difficulty with concentration/attention, and mood problems. Additional rare side effects of topiramate are depression, hallucinations or paranoia, vision problems that may be associated with eye pain, deep vein thrombosis, hyperglycemia, hair loss, impotence, anorgasmia, and constipation. Rare narrow angle-closure glaucoma can occur early in treatment, and usually remits. ${ }^{59}$ At higher doses there is also a rare risk of oligohydrosis, which can result in potentially fatal hyperthermia; this is more common in younger patients. ${ }^{60}$ Topiramate is a carbonic anhydrase inhibitor, which has an uncertain significance for migraine prevention, but has implications for AE. Hyperchloremic acidosis, rarely clinically significant, can occur in more than $10 \%$ of patients. Although most patients are asymptomatic, the acidosis can lead to an increased risk of renal calculi and osteomalacia, and thus may require blood monitoring of $\mathrm{pH}$, bicarbonate and chloride. Nephrolithiasis occurs at a rate of $1 \%$ as a byproduct of this topiramate carbonic anhydrase inhibition. ${ }^{59}$

Generally, AE appear to be most pronounced at the beginning of topiramate treatment within the first 2 months and often resolve over time. The onset of AE that were actually treatment limiting in large published trials tended to occur during the titration period. ${ }^{11}$ For example, the overall incidence of paresthesia was $50.5 \%$, while the cumulative incidence was $45.5 \%$ on day 28 and $49.5 \%$ on day 42 of the DB phase. The incidence of "any cognitive symptoms", loss of appetite and fatigue also were most common within the titration phase. ${ }^{61}$ This led to the suggestion that if a patient has not experienced one of these $\mathrm{AE}$ within the first or second month, it will most likely not occur.

While weight gain is a common problem in patients receiving traditional migraine prophylaxis, ${ }^{62}$ one interesting effect of topiramate is weight loss in many patients. It appears that this effect is limited, however, and that it is more pronounced in patients with a higher body mass index. In the pooled analysis by Bussone et al. the mean weight loss at the 6 months endpoint was $-2.5 \mathrm{~kg}$ compared to $0.1 \mathrm{~kg}$ in the placebo group, but in overweight and obese patients it was $-3.1 \mathrm{~kg}$ and $3 \mathrm{~kg}$ respectively. ${ }^{37}$

In the two studies investigating topiramate in a longer treatment period adverse events were similar to those reported in the shorter trials. ${ }^{40,41}$ Long-term treatment is not associated with greater risk for the patient, as most AE occur within the first 8 weeks of treatment. For interactions with other medications refer to Table 3 .

\section{Topiramate in pregnancy}

The safety of topiramate in pregnancy is largely unknown. Only a few trials with small sample sizes have investigated this problem in human pregnancies. ${ }^{63-65}$ Topiramate is known to cross the human placenta and is secreted in the milk. ${ }^{66} \mathrm{In}$ animal experiments it was found that topiramate is teratogenic in mice, rabbits, and rats. ${ }^{67}$ On a molecular basis topiramate inhibits histone deacetylases (HDACs) in human cells. ${ }^{68}$ Conventional HDAC inhibitors mimic the defects related 
Table 3 Withdrawal rates in the three MIGR trials

\begin{tabular}{|c|c|c|c|c|c|c|c|c|c|c|c|c|}
\hline \multirow[b]{2}{*}{ Group (TPM dose in mg) } & \multicolumn{4}{|c|}{ MIGR-00 I Silberstein et al ${ }^{35}$} & \multicolumn{4}{|c|}{ MIGR-002 Brandes et $\mathrm{al}^{36}$} & \multicolumn{4}{|c|}{ MIGR-003 Diener et al ${ }^{19}$} \\
\hline & 50 & 100 & 200 & PLC & 50 & 100 & 200 & PLC & 100 & 200 & PROP & PLC \\
\hline No of patients randomized & 125 & 128 & 117 & 117 & 120 & 122 & $|2|$ & 120 & $|4|$ & 144 & 144 & 146 \\
\hline $\begin{array}{l}\mathrm{n} \text { withdrawal after } \\
\text { randomization (withdrawal } \\
\text { in \% of patients randomized) }\end{array}$ & $\begin{array}{l}57 \\
(45.6)\end{array}$ & $\begin{array}{l}45 \\
(35.2)\end{array}$ & $\begin{array}{l}72 \\
(6 I .5)\end{array}$ & $\begin{array}{l}48 \\
(66.7)\end{array}$ & $\begin{array}{l}61 \\
(50.8)\end{array}$ & $\begin{array}{l}59 \\
(48.4)\end{array}$ & $\begin{array}{l}51 \\
(42.1)\end{array}$ & $\begin{array}{l}57 \\
(47.5)\end{array}$ & $\begin{array}{l}47 \\
(33.4)\end{array}$ & $\begin{array}{l}79 \\
(54.9)\end{array}$ & $\begin{array}{l}42 \\
(29.2)\end{array}$ & $\begin{array}{l}47 \\
(32.2)\end{array}$ \\
\hline $\begin{array}{l}\text { Withdrew due to AEs } \\
\text { (\% of overall withdrawal) }\end{array}$ & $\begin{array}{l}21 \\
(36.8)\end{array}$ & $\begin{array}{l}24 \\
(53.3)\end{array}$ & $\begin{array}{l}38 \\
(52.8)\end{array}$ & $\begin{array}{l}11 \\
(22.9)\end{array}$ & $\begin{array}{l}20 \\
(32.8)\end{array}$ & $\begin{array}{l}32 \\
(54.2)\end{array}$ & $\begin{array}{l}25 \\
(49.0)\end{array}$ & $\begin{array}{l}14 \\
(24.6)\end{array}$ & $\begin{array}{l}37 \\
(78.7)\end{array}$ & $\begin{array}{l}63 \\
(79.7)\end{array}$ & $\begin{array}{l}29 \\
(69.0)\end{array}$ & $\begin{array}{l}15 \\
(31.9)\end{array}$ \\
\hline $\begin{array}{l}\text { Withdrew due to lack } \\
\text { of efficacy (\% of overall } \\
\text { withdrawal) }\end{array}$ & $\begin{array}{l}10 \\
(17.5)\end{array}$ & $\begin{array}{l}6 \\
(13.3)\end{array}$ & $\begin{array}{l}8 \\
(I I . I)\end{array}$ & $\begin{array}{l}21 \\
(43.7)\end{array}$ & $\begin{array}{l}15 \\
(24.6)\end{array}$ & $\begin{array}{l}\text { II } \\
(18.6)\end{array}$ & $\begin{array}{l}12 \\
(22.5)\end{array}$ & $\begin{array}{l}21 \\
(36.8)\end{array}$ & $\begin{array}{l}1 \\
(2.1)\end{array}$ & $\begin{array}{l}2 \\
(2.5)\end{array}$ & $\begin{array}{l}3 \\
(7.1)\end{array}$ & $\begin{array}{l}13 \\
(27.7)\end{array}$ \\
\hline $\begin{array}{l}\text { Withdrew due to subjects } \\
\text { choice (\% of overall) }\end{array}$ & $\begin{array}{l}10 \\
(17.5)\end{array}$ & $\begin{array}{l}6 \\
(13.3)\end{array}$ & $\begin{array}{l}8 \\
(I I . I)\end{array}$ & $\begin{array}{l}3 \\
(6.3)\end{array}$ & $\begin{array}{l}8 \\
(13.1)\end{array}$ & $\begin{array}{l}6 \\
(10.2)\end{array}$ & $\begin{array}{l}5 \\
(9.8)\end{array}$ & $\begin{array}{l}7 \\
(12.3)\end{array}$ & $\begin{array}{l}5 \\
(10.6)\end{array}$ & $\begin{array}{l}8 \\
(10.1)\end{array}$ & $\begin{array}{l}3 \\
(7.1)\end{array}$ & $\begin{array}{l}7 \\
(14.9)\end{array}$ \\
\hline $\begin{array}{l}\text { No patients in intent } \\
\text { to treat cohorts }\end{array}$ & 117 & 125 & 112 & 115 & 117 & 120 & 117 & 114 & 139 & 143 & 143 & 143 \\
\hline $\begin{array}{l}\text { No withdrawal after intent } \\
\text { to treat }\end{array}$ & 49 & 42 & 67 & 46 & 58 & 57 & 47 & 51 & 45 & 78 & $4 I$ & 44 \\
\hline
\end{tabular}

Abbreviations: AE, adverse events; TMP, topiramate; PLC, placebo; PROP, propranolol.

to prenatal exposure to valproic acid and the inhibition of HDACs by valproic acid was suggested to possibly represent the molecular starting point of its teratogenic risk. ${ }^{69}$ In 2007, a study investigating 52 pregnancies exposed to topiramate treatment showed a significant decrease in birth weights. ${ }^{64}$ However, the authors concluded that the risk for structural defects was not increased in babies of patients treated with topiramate during pregnancy. As the investigated study population was small, data do not permit a positive or negative conclusion. It should be kept in mind that lower birth weight is one of the expected effects of an HDAC inhibitor. In a recent analysis from the UK, 178 live births (resulting from 203 pregnancies) of mothers who became pregnant during topiramate intake were analyzed. ${ }^{65}$ Only 70 of these patients received antiepileptic drug monotherapy. Their rate of major congenital malformations was comparable to those of other antiepileptic drugs ( 3 malformations in 70 live births). The rates in antiepileptic drug polytherapy with topiramate were even higher (especially in combinations containing valproate). So the rates of oral clefts were 11 times and those of hypospadias 14 times higher than background rates.

In conclusion, studies analyzing topiramate in pregnancy are small and rare. As all studies analyzed patients with epilepsy, sample-rates for topiramate monotherapy are even smaller. As there are hints for teratogenic risk in animal, molecular and clinical experiments, it must be concluded that the assessment of safety in pregnancy requires further investigations and treatment cannot be recommended at this time.

\section{Topiramate in pediatric migraine}

Migraine occurs in $10.6 \%$ of children and adolescents between the ages of 5 and 15 years and $28 \%$ of adolescents between the ages of 15 and 19 years. ${ }^{70-75}$ Currently, no drugs have been approved by the Food and Drug Administration (FDA) for migraine prophylaxis in pediatric patients. Three randomized, controlled trials have been conducted, however, including a total of 212 children and adolescents between 6 and 17 years. Topiramate at $100 \mathrm{mg} /$ day, but not $50 \mathrm{mg} /$ day, significantly reduced the monthly migraine day rate from baseline versus placebo during the 12-week double-blind treatment phase. ${ }^{76-78}$ Effective dosages reported throughout these trials ranged from 2 to $3 \mathrm{mg} / \mathrm{kg} /$ day and are much lower than the dosages usually required for the adjunctive treatment of epilepsy ( 5 to $9 \mathrm{mg} / \mathrm{kg} /$ day) in young children. Safety and tolerability was comparable to reports from adult study populations. Most common side effects in children were weight loss (10.2\%), anorexia (13\%), abdominal pain (10.2\%), difficulties in concentration, somnolence/sedation (8.3\%), and paresthesia $(8.3 \%)$. Side effects tended to decline over time and dropout rates due to side effects were very low in the different trials (range $0 \%$ to $6.3 \%$ ). Assessment of PedMIDAS (MIDAS for pediatric and adolescent patients) results showed a significant decrease in absent school days and an improvement in the quality of life in these children. ${ }^{79}$

\section{Patient preference}

Few trials have directly investigated efficacy differences between different prophylactic treatment options in 
migraine ${ }^{80-83}$ which makes difficult an evidence-based decision on the drug of choice on the basis of efficacy. Patient preference, co-morbidities, contraindications and side effects will have to be considered for each individual patient. Topiramate generally is recommended in patients for whom beta-receptor-antagonists are contraindicated (eg, in chronic obstructive pulmonary disease or asthma) or unfavorable for the patient (eg, in obese patients, decreased sexual ability, hair loss). Topiramate may be preferred to other migraine preventive drugs with similar evidence for efficacy when patients may have an additive effect to their previously existing medication, eg, in patients with concomitant epilepsy topiramate may be the preferred choice, while amitriptyline is not. In patients with migraine and obesity it may be a good choice because weight gain is a common side effect in classical migraine preventive treatment options such as beta-blockers, valproic acid and flunarizine. Especially in young women weight gain poses serious concern in terms of compliance. Some patients may suffer from more than one headache disorder, and because there is evidence that topiramate may be effective in the treatment of cluster headache ${ }^{84-86}$ and other primary headache disorders it might be the drug of choice for these patients. Many further side effects and contraindications have to be taken into account in making a definite treatment decision (see Table 1 for an overview). Different forms of drug application may also be helpful in reaching a treatment decision in favor of topiramate, eg, topiramate is available in capsules and could be sprinkled on food if a patient has problems swallowing pills.

\section{Combination of topiramate with other preventive drugs}

As different migraine preventive drugs have different modes of action and additive effects might be suspected, combination therapy might help patients who are refractory to monotherapy. ${ }^{25,87}$ However, large controlled clinical trials are lacking in this regard. Some smaller studies have been conducted. In an open label trial testing the combination of topiramate with a beta-blocker in migraine patients previously resistant to at least two medications in monotherapy, 58 patients received combined treatment. ${ }^{88}$ While $62 \%$ of patients showed at least moderate response $(>50 \%$ reduction in frequency), nearly half (44\%) showed an excellent $(>75 \%)$ response to combination treatment. However, $17 \%$ discontinued due to adverse events, although they had tolerated both drugs in monotherapy previously. The authors concluded that combination therapy is reasonable, considering the complementary mechanism of action, as a potential strategy in patients with refractory migraine. In a singlecenter, double-blind, randomized, controlled trial investigating 73 patients with migraine headache, ${ }^{89}$ the effectiveness of amitriptyline and topiramate in the prevention of migraine attacks in comparison to monotherapy of each drug was evaluated. In all three treatment groups (amitriptyline alone; topriamate alone; amitriptyline and topiramate) improvements in frequency, duration and severity of migraine were significant (all variables $P<0.001$ ). Improvement in depressive state and consumption of medications was also reported (both variables $P<0.001$ ). Furthermore, patients receiving amitriptyline alone or the combination treatment had better depression scores than the topiramate monotherapy group. The authors concluded that the combination of amitriptyline and topiramate may be beneficial for patients with migraine and co-morbid depression. Although the combination of topiramate with other preventive treatment may be effective in treating refractory migraine, further research is needed.

\section{Conclusion}

There is sufficient scientific evidence that topiramate is effective in reducing migraine frequency at a dose of $100 \mathrm{mg}$ /day in patients suffering from episodic migraine with or without aura. Topiramate $100 \mathrm{mg}$ /day also appears to be effective in the treatment of CM. A lower dose of $50 \mathrm{mg}$ /day may also be effective. General treatment effects appear to be independent from medication overuse in CM, and thus it may not be necessary to withdraw patients from medication overuse prior to attempting treatment with topiramate. Data on treatment periods longer than 14 months are still unavailable, but the trials performed give no reason to raise concern about efficacy or safety in long-term treatment. Topiramate is generally well tolerated with moderate side effects in migraine patients. Common side effects were paresthesias, fatigue, nausea, anorexia and weight loss within the first 8 weeks of treatment. Treatment in pediatric migraine (age 6 to 17 years) was proven safe and effective. Assessment of safety in pregnancy requires further investigations and cannot be recommended at this time.

\section{Disclosures}

The authors have nothing to declare.

\section{References}

1. Jensen R, Stovner LJ. Epidemiology and comorbidity of headache. Lancet Neurol. 2008;7(4):354-361.

2. Stovner L, Hagen K, Jensen R, et al. The global burden of headache: a documentation of headache prevalence and disability worldwide. Cephalalgia. 2007;27(3):193-210. 
3. The International Classification of Headache Disorders. 2nd edition. Cephalalgia. 2004;24 Suppl 1:9-160.

4 Benseñor IM, Lotufo PA, Goulart AC, Menezes PR, Scazufca M. The prevalence of headache among elderly in a low-income area of São Paulo, Brazil. Cephalalgia. 2008;28(4):329-333.

5. Zwart J, Dyb G, Holmen TL, Stovner LJ, Sand T. The prevalence of migraine and tension-type headaches among adolescents in Norway. The Nord-Trøndelag Health Study (Head-HUNT-Youth), a large population-based epidemiological study. Cephalalgia. 2004;24(5): 373-379.

6. Obermann M, Yoon M, Dommes P, et al. Prevalence of trigeminal autonomic symptoms in migraine: a population-based study. Cephalalgia. 2007;27(6):504-509.

7. Barbanti P, Fabbrini G, Pesare M, Vanacore N, Cerbo R. Unilateral cranial autonomic symptoms in migraine. Cephalalgia. 2002;22(4):256-259.

8. Kurth T, Schürks M, Logroscino G, Gaziano JM, Buring JE. Migraine, vascular risk, and cardiovascular events in women: prospective cohort study. BMJ. 2008;337:a636.

9. Kelman L. The aura: a tertiary care study of 952 migraine patients. Cephalalgia. 2004;24(9):728-734

10. Lipton RB, Scher AI, Kolodner K, et al. Migraine in the United States: epidemiology and patterns of health care use. Neurology. 2002;58(6):885-894

11. Mattsson P, Lundberg PO. Characteristics and prevalence of transient visual disturbances indicative of migraine visual aura. Cephalalgia. 1999;19(5):479-484.

12. Reuter U, Rio MSD, Diener H, et al. Migraines with and without aura and their response to preventive therapy with topiramate. Cephalalgia. 2009 Sep 3. Epub ahead of print.

13. Giffin NJ, Ruggiero L, Lipton RB, et al. Premonitory symptoms in migraine: an electronic diary study. Neurology. 2003;60(6):935-940.

14. MacGregor EA, Brandes J, Eikermann A. Migraine prevalence and treatment patterns: the global Migraine and Zolmitriptan Evaluation survey. Headache. 2003;43(1):19-26.

15. Cevoli S, D'Amico D, Martelletti P, et al. Underdiagnosis and undertreatment of migraine in Italy: a survey of patients attending for the first time 10 headache centres. Cephalalgia. 2009 Oct 20. Epub ahead of print.

16. Members of the task force, Evers S, Afra J, Frese A, et al. EFNS guideline on the drug treatment of migraine - report of an EFNS task force. Eur J Neurol. 2006;13(6):560-572.

17. Silberstein SD. Practice parameter: evidence-based guidelines for migraine headache (an evidence-based review): report of the Quality Standards Subcommittee of the American Academy of Neurology. Neurology. 2000;55(6):754-762.

18. May TW, Rambeck B, Jürgens U. Serum concentrations of topiramate in patients with epilepsy: influence of dose, age, and comedication. Ther Drug Monit. 2002;24(3):366-374.

19. Diener H, Tfelt-Hansen P, Dahlöf C, et al. Topiramate in migraine prophylaxis-results from a placebo-controlled trial with propranolo as an active control. J Neurol. 2004;251(8):943-950.

20. Zona C, Ciotti MT, Avoli M. Topiramate attenuates voltage-gated sodium currents in rat cerebellar granule cells. Neurosci Lett. 1997;231(3): 123-126.

21. Zhang X, Velumian AA, Jones OT, Carlen PL. Modulation of highvoltage-activated calcium channels in dentate granule cells by topiramate. Epilepsia. 2000;41 Suppl 1:S52-S60.

22. Qian J, Noebels JL. Topiramate alters excitatory synaptic transmission in mouse hippocampus. Epilepsy Res. 2003;55(3):225-233.

23. White HS, Brown SD, Woodhead JH, Skeen GA, Wolf HH. Topiramate modulates GABA-evoked currents in murine cortical neurons by a nonbenzodiazepine mechanism. Epilepsia. 2000;41 Suppl 1:S17-S20.

24. Shank RP, Doose DR, Streeter AJ, Bialer M. Plasma and whole blood pharmacokinetics of topiramate: the role of carbonic anhydrase. Epilepsy Res. 2005;63(2-3):103-112.

25. Evers S. Treatment of migraine with prophylactic drugs. Expert Opin Pharmacother. 2008;9(15):2565-2573.

26. Rabkin R, Stables DP, Levin NW, Suzman MM. The prophylactic value of propranolol in angina pectoris. Am J Cardiol. 1966;18(3):370-383.
27. Classification and diagnostic criteria for headache disorders, cranial neuralgias and facial pain. Headache Classification Committee of the International Headache Society. Cephalalgia. 1988;8 Suppl 7:1-96.

28. Lipton RB, Bigal ME, Diamond M, et al. Migraine prevalence, disease burden, and the need for preventive therapy. Neurology. 2007;68(5): $343-349$.

29. Morillo LE, Alarcon F, Aranaga N, et al. Clinical characteristics and patterns of medication use of migraneurs in Latin America from 12 cities in 6 countries. Headache. 2005;45(2):118-126.

30. Lucas C, Chaffaut C, Artaz M, Lantéri-Minet M. FRAMIG 2000: medical and therapeutic management of migraine in France. Cephalalgia. 2005;25(4):267-279.

31. Von Seggern RL, Mannix LK, Adelman JU. Efficacy of topiramate in migraine prophylaxis: a retrospective chart analysis. Headache 2002;42(8):804-809.

32. Young WB, Hopkins MM, Shechter AL, Silberstein SD. Topiramate: a case series study in migraine prophylaxis. Cephalalgia. 2002;22(8):659-663.

33. Storey JR, Calder CS, Hart DE, Potter DL. Topiramate in migraine prevention: a double-blind, placebo-controlled study. Headache 2001;41(10):968-975.

34. Edwards KR, Potter DL, Wu S, Kamin M, Hulihan J. Topiramate in the preventive treatment of episodic migraine: a combined analysis from pilot, double-blind, placebo-controlled trials. CNS Spectr. 2003; 8(6):428-432.

35. Silberstein SD, Neto W, Schmitt J, Jacobs D, Group MIGRS. Topiramate in migraine prevention: results of a large controlled trial. Arch Neurol. 2004;61(4):490-495.

36. Brandes JL, Saper JR, Diamond M, et al. Topiramate for migraine prevention: a randomized controlled trial. JAMA. 2004;291(8):965-973.

37. Bussone G, Diener H, Pfeil J, Schwalen S. Topiramate $100 \mathrm{mg} /$ day in migraine prevention: a pooled analysis of double-blind randomised controlled trials. Int J Clin Pract. 2005;59(8):961-968.

38. Verspeelt J, De Locht P, Amery WK. Post-marketing cohort study comparing the safety and efficacy of flunarizine and propranolol in the prophylaxis of migraine. Cephalalgia. 1996;16(5):328-336.

39. Linde K, Rossnagel K. Propranolol for migraine prophylaxis. Cochrane Database Syst Rev. 2004;(2):CD003225.

40. Rapoport A, Mauskop A, Diener H, Schwalen S, Pfeil J. Long-term migraine prevention with topiramate: open-label extension of pivotal trials. Headache. 2006;46(7):1151-1160.

41. Diener H, Agosti R, Allais G, et al. Cessation versus continuation of 6-month migraine preventive therapy with topiramate (PROMPT): a randomised, double-blind, placebo-controlled trial. Lancet Neurol. 2007;6(12):1054-1062.

42. Kosinski M, Bayliss MS, Bjorner JB, et al. A six-item short-form survey for measuring headache impact: the HIT-6. Qual Life Res. 2003;12(8):963-974.

43. Lipton RB, Stewart WF, Sawyer J, Edmeads JG. Clinical utility of an instrument assessing migraine disability: the Migraine Disability Assessment (MIDAS) questionnaire. Headache. 2001;41(9):854-861.

44. Ware J, Kosinski M, Keller SD. A 12-Item Short-Form Health Survey: construction of scales and preliminary tests of reliability and validity. Med Care. 1996;34(3):220-233.

45. Castillo J, Muñoz P, Guitera V, Pascual J. Kaplan Award 1998. Epidemiology of chronic daily headache in the general population. Headache. 1999;39(3):190-196.

46. Scher AI, Stewart WF, Liberman J, Lipton RB. Prevalence of frequent headache in a population sample. Headache. 1998;38(7):497-506.

47. Silberstein SD, Lipton RB, Sliwinski M. Classification of daily and near-daily headaches: field trial of revised IHS criteria. Neurology. 1996;47(4):871-875.

48. Katsarava Z, Schneeweiss S, Kurth T, et al. Incidence and predictors for chronicity of headache in patients with episodic migraine. Neurology. 2004;62(5):788-790.

49. Olesen J, Bousser M, Diener H, et al. New appendix criteria open for a broader concept of chronic migraine. Cephalalgia. 2006;26(6):742-746. 
50. Mei D, Ferraro D, Zelano G, et al. Topiramate and triptans revert chronic migraine with medication overuse to episodic migraine. Clin Neuropharmacol. 2006;29(5):269-275.

51. Silvestrini M, Bartolini M, Coccia M, et al. Topiramate in the treatment of chronic migraine. Cephalalgia. 2003;23(8):820-824.

52. Bartolini M, Silvestrini M, Taffi R, et al. Efficacy of topiramate and valproate in chronic migraine. Clin Neuropharmacol. 2005;28(6):277-279.

53. Limmroth V, Biondi D, Pfeil J, Schwalen S. Topiramate in patients with episodic migraine: reducing the risk for chronic forms of headache. Headache. 2007;47(1):13-21.

54. Silberstein SD, Lipton RB, Dodick DW, et al. Efficacy and safety of topiramate for the treatment of chronic migraine: a randomized, doubleblind, placebo-controlled trial. Headache. 2007;47(2):170-180.

55. Diener H, Bussone G, Oene JCV, et al. Topiramate reduces headache days in chronic migraine: a randomized, double-blind, placebocontrolled study. Cephalalgia. 2007;27(7):814-823.

56. Diener H, Dodick DW, Goadsby PJ, et al. Utility of topiramate for the treatment of patients with chronic migraine in the presence or absence of acute medication overuse. Cephalalgia. 2009;29(10):1021-1027.

57. Silberstein S, Lipton R, Dodick D, et al. Topiramate treatment of chronic migraine: a randomized, placebo-controlled trial of quality of life and other efficacy measures. Headache. 2009;49(8):1153-1162.

58. Silberstein SD. Control of topiramate-induced paresthesias with supplemental potassium. Headache. 2002;42(1):85.

59. Lyseng-Williamson KA, Yang LPH. Topiramate: a review of its use in the treatment of epilepsy. Drugs. 2007;67(15):2231-2256.

60. Ziad EK, Rahi AC, Hamdan SA, Mikati MA. Age, dose, and environmental temperature are risk factors for topiramate-related hyperthermia. Neurology. 2005;65(7):1139-1140.

61. Láinez MJA, Freitag FG, Pfeil J, et al. Time course of adverse events most commonly associated with topiramate for migraine prevention. Eur J Neurol. 2007;14(8):900-906.

62. Taylor FR. Weight change associated with the use of migraine-preventive medications. Clin Ther. 2008;30(6):1069-1080.

63. Morrow J, Russell A, Guthrie E, et al. Malformation risks of antiepileptic drugs in pregnancy: a prospective study from the UK Epilepsy and Pregnancy Register. J Neurol Neurosurg Psychiatr. 2006;77(2):193-198.

64. Ornoy A, Zvi N, Arnon J, et al. The outcome of pregnancy following topiramate treatment: a study on 52 pregnancies. Reprod Toxicol. 2008;25(3):388-389.

65. Hunt S, Russell A, Smithson WH, et al. Topiramate in pregnancy: preliminary experience from the UK Epilepsy and Pregnancy Register. Neurology. 2008;71(4):272-276.

66. Ohman I, Vitols S, Luef G, Söderfeldt B, Tomson T. Topiramate kinetics during delivery, lactation, and in the neonate: preliminary observations. Epilepsia. 2002;43(10):1157-1160.

67. Palmieri C, Canger R. Teratogenic potential of the newer antiepileptic drugs: what is known and how should this influence prescribing? CNS Drugs. 2002;16(11):755-764.

68. Eyal S, Yagen B, Sobol E, et al. The activity of antiepileptic drugs as histone deacetylase inhibitors. Epilepsia. 2004;45(7):737-744.

69. Gurvich N, Berman MG, Wittner BS, et al. Association of valproateinduced teratogenesis with histone deacetylase inhibition in vivo. FASEB J. 2005;19(9):1166-1168.

70. Lewis DW, Yonker M, Winner P, Sowell M. The treatment of pediatric migraine. Pediatr Ann. 2005;34(6):448-460.
71. Stewart WF, Linet MS, Celentano DD, Van Natta M, Ziegler D. Age- and sex-specific incidence rates of migraine with and without visual aura. Am J Epidemiol. 1991;134(10):1111-1120.

72. Stewart WF, Lipton RB, Celentano DD, Reed ML. Prevalence of migraine headache in the United States. Relation to age, income, race, and other sociodemographic factors. JAMA. 1992;267(1):64-69.

73. Abu-Arefeh I, Russell G. Prevalence of headache and migraine in schoolchildren. BMJ. 1994;309(6957):765-769.

74. Hershey AD. What is the impact, prevalence, disability, and quality of life of pediatric headache? Curr Pain Headache Rep. 2005;9(5): 341-344.

75. Pakalnis A. Pediatric migraine: new diagnostic strategies and treatment options. Expert Rev Neurother. 2006;6(3):291-296

76. Lewis D, Winner P, Saper J, et al. Randomized, double-blind, placebocontrolled study to evaluate the efficacy and safety of topiramate for migraine prevention in pediatric subjects 12 to 17 years of age. Pediatrics. 2009;123(3):924-934.

77. Lakshmi CVS, Singhi P, Malhi P, Ray M. Topiramate in the prophylaxis of pediatric migraine: a double-blind placebo-controlled trial. J Child Neurol. 2007;22(7):829-835.

78. Winner P, Pearlman EM, Linder SL, et al. Topiramate for migraine prevention in children: a randomized, double-blind, placebo-controlled trial. Headache. 2005;45(10):1304-1312.

79. Ferraro D, Trapani GD. Topiramate in the prevention of pediatric migraine: literature review. J Headache Pain. 2008;9(3):147-150.

80. Diener HC, Matias-Guiu J, Hartung E, et al. Efficacy and tolerability in migraine prophylaxis of flunarizine in reduced doses: a comparison with propranolol $160 \mathrm{mg}$ daily. Cephalalgia. 2002;22(3):209-221.

81. Diener HC, Hartung E, Chrubasik J, et al. A comparative study of oral acetylsalicyclic acid and metoprolol for the prophylactic treatment of migraine. A randomized, controlled, double-blind, parallel group phase III study. Cephalalgia. 2001;21(2):120-128.

82. Diener HC, Föh M, Iaccarino C, et al. Cyclandelate in the prophylaxis of migraine: a randomized, parallel, double-blind study in comparison with placebo and propranolol. The Study group. Cephalalgia. 1996;16(6):441-447.

83. Dodick DW, Freitag F, Banks J, et al. Topiramate versus amitriptyline in migraine prevention: a 26-week, multicenter, randomized, double-blind, double-dummy, parallel-group noninferiority trial in adult migraineurs. Clin Ther. 2009;31(3):542-559.

84. Wheeler SD, Carrazana EJ. Topiramate-treated cluster headache. Neurology. 1999;53(1):234-236.

85. Förderreuther S, Mayer M, Straube A. Treatment of cluster headache with topiramate: effects and side-effects in five patients. Cephalalgia. 2002;22(3):186-189.

86. Láinez MJA, Pascual J, Pascual AM, et al. Topiramate in the prophylactic treatment of cluster headache. Headache. 2003;43(7):784-789.

87. Mathew NT. Dynamic optimization of chronic migraine treatment: current and future options. Neurology. 2009;72(5 Suppl):S14-S20.

88. Pascual J, Rivas MT, Leira R. Testing the combination beta-blocker plus topiramate in refractory migraine. Acta Neurol Scand. 2007;115(2): 81-83.

89. Keskinbora K, Aydinli I. A double-blind randomized controlled trial of topiramate and amitriptyline either alone or in combination for the prevention of migraine. Clin Neurol Neurosurg. 2008;110(10): 979-984.
Neuropsychiatric Disease and Treatment

\section{Publish your work in this journal}

Neuropsychiatric Disease and Treatment is an international, peerreviewed journal of clinical therapeutics and pharmacology focusing on concise rapid reporting of clinical or pre-clinical studies on a range of neuropsychiatric and neurological disorders. This journal is indexed on PubMed Central, the 'PsycINFO' database and CAS, and is the official

\section{Dovepress}

journal of The International Neuropsychiatric Association (INA). The manuscript management system is completely online and includes a very quick and fair peer-review system, which is all easy to use. Visit http://www.dovepress.com/testimonials.php to read real quotes from published authors. 